\title{
Autonomic Mechanisms in Hemodynamic
} Responses to Isometric Exercise

\author{
C. Edwin Martin, James A. Shaver, Donald F. Leon, Mark E. Thompson, \\ Pesara S. Reddy, and James J. Leonard
}

From the Department of Medicine, Division of Cardiology, University of

Pittsburgh School of Medicine, Pittsburgh, Pennsylvania 15213

\begin{abstract}
A B S T R A C T Selective autonomic blockade with intravenous propranolol, practolol, atropine, and combined atropine-propranolol was utilized to elucidate the role of the autonomic nervous system in the hemodynamic responses in young adult male volunteers to handgrip sustained at $30 \%$ of maximal voluntary contraction for $3 \mathrm{~min}$. The initial $30 \mathrm{~s}$ of the tachycardia response was found to be mediated by withdrawal of vagal dominance, as evidenced by blockade of this response by prior atropinization. The mid and late portion of the heart rate response curve was demonstrated to be sympathetic in origin, since it was unaffected by atropine, but was suppressed by combined atropine-propranolol blockade. Sympathetic stimulation appears to be a secondary mechanism for increasing the heart rate, however, as it becomes operative only after the first mechanism of vagal withdrawal has been utilized. This was confirmed by the finding that beta adrenergic receptor blockade alone had little effect on the heart rate response curve.

The pressor response to handgrip was accompanied by increased cardiac output and no change in calculated systemic vascular resistance. After propranolol, handgrip resulted in increased peripheral resistance and an equivalent rise in arterial pressure, but no increase in cardiac output. It was concluded that the increase in resistance was the result of sympathetically induced vasoconstriction. This response was shown to be independent of peripheral beta adrenergic receptor blockade by the use of practolol, a cardio-selective beta adrenergic receptor-blocking drug which caused identical hemo-
\end{abstract}

Portions of this study were presented previously in abstract form. Martin, C. E., D. F. Leon, M. E. Thompson, and J. A. Shaver. 1971. Modification of the cardiovascular responses to sustained, handgrip by $\beta$-adrenergic blockade. Circulation. 44: 198.

Received for publication 3 November 1973 and in revised form 12 December 1973. dynamic responses to those observed after propranolol. Left ventricular ejection time (corrected for heart rate) was prolonged by handgrip. The increased afterload imposed on the left ventricle by sustained handgrip may explain the prolongation of ejection time index. Preejection period was prolonged by SHG after propranolol and shortened after atropine. In addition to confirming the previously defined role of the parasympathetic nervous system, this study delineates the role of the sympathetic nervous system in the heart rate and pressor responses to sustained handgrip.

\section{INTRODUCTION}

The cardiovascular responses to sustained isometric exercise have been studied and well defined in volunteers. $(1,2)$. Characteristically modest increases in heart rate and cardiac output occur, while increases in systolic and diastolic arterial pressure are more pronounced. The relative increases in cardiac output and mean blood pressure are such that calculated systemic vascular resistance $(\mathrm{SVR})^{1}$ is unchanged. Recently, sustained handgrip ( $\mathrm{SHG}$ ) has become clinically popular as a cardiac stress test (3-7). Hemodynamic studies during such testing in patients with cardiovascular disease have shown variable responses, deviating significantly from those of the volunteers. In some patients with hypertension or left ventricular dysfunction, as well as in certain elderly individuals, cardiac output does not rise, despite normal heart rate and pressor responses. In these patients, the pressure rise is accompanied by an increase in SVR (7-11).

The autonomic effector mechanisms by which circulatory responses to isometric exercise occur remain un-

${ }^{1}$ Abbreviations used in this paper: LVET, left ventricular ejection time; LVETI, left ventricular ejection time index; PEP, preejection period; SHG, sustained hand grip; SVR, systemic vascular resistance. 
clear. Although the tachycardia response is most likely initiated by withdrawal of vagal tone, the role of sympathetic stimulation has not been elucidated. The relative roles of vagal withdrawal and sympathetic stimulation in the pressor response need to be clarified (12, 13). Therefore, the present study was proposed in order to $(a)$ delineate the effector mechanism of heart rate control during $\mathrm{SHG}$; $(b)$ explore the mechanism of the pressor response and the possible role of sympathetically mediated vasoconstriction; and $(c)$ evaluate left ventricular performance by the technique of systolic time intervals during SHG, before and after autonomic blockade.

\section{METHODS}

Studies were performed on male volunteers, aged 19-38 yr (mean $=25)$. Initially, each subject was familiarized with handgrip dynamometer (Stoelting Co., Chicago, Ill.) and the maximal voluntary contraction of subjects was determined with this instrument. All studies were performed on supine subjects.

A $20-\mathrm{cm}$ polyethylene cannula (PE-160, Clay-Adams Inc., Parsippany, N. J.) was introduced into the brachial artery by Seldinger technique, and central venous pressure was monitored through a $90-\mathrm{cm}$ polyethylene cannula (PE-50, Clay Adams Inc.). The indirect carotid pulse was recorded by a funnel-shaped pickup attached to a strain gauge (P23Db, Statham Instruments, Inc., Oxnard, Calif.) which was held in place manually. A precordial microphone was positioned to record optimally the aortic component of the second heart sound. The electrocardiogram was monitored by using a lead which showed a sharp onset of the QRS complex. The cannulae were attached to strain gauges, and all recordings were made on a polybeam (DR12, Electronics for Medicine, Inc., White Plains, N. Y.) recorder at $100 \mathrm{~mm} / \mathrm{s}$ paper speed. Cardiac outputs were determined by the indicator dilution method using indocyanine green.

During the first phase of the experimental protocol, baseline measurements were made, and before drug interventions, each subject performed SHG at $30 \%$ of his predetermined maximal voluntary capacity. We chose this level, judging it to be tolerable to most subjects when held for $3 \mathrm{~min}^{2}$ During SHG, the electrocardiogram and arterial and venous pressures were monitored continuously. $2 \mathrm{~min}$ and $45 \mathrm{~s}$ after beginning of exercise, cardiac output was again measured, followed in rapid succession by measurement of pressure contours and systolic time intervals. Measurements were completed by $3.5 \mathrm{~min}$, and $\mathrm{SHG}$ was discontinued.

A 15-min rest period was allowed between SHG periods to minimize fatigue from the preceding test. ${ }^{3}$ Base-line

'Bruce, Lind, Franklin, Muir, MacDonald, McNicol, and Donald (14) found that $30 \%$ of maximal voluntary contraction was tolerated for $236 \pm 44 \mathrm{~s}$ on the first contraction and $177 \pm 31 \mathrm{~s}$ on the second contraction after a 10-min rest period.

${ }^{3}$ Lind (15) found full recovery of muscle function after sustained handgrip to require several hours. However, the heart rate and blood pressure responses to $3 \mathrm{~min}$ of $30 \%$ maximal voluntary contraction do not appear to differ significantly between first and second bouts of SHG performed 2 min apart (14). measurements were first repeated to assure a return to previous resting levels. Then, during phase two of the protocol, SHG was performed after a drug intervention.

(a) Seven subjects were selected to receive propranolol, $0.15 \mathrm{mg} / \mathrm{kg}$, given i.v. over a 2-min period. ${ }^{*}$ The hemodynamic measurements were repeated $5 \mathrm{~min}$ after completion of the propranolol infusion. SHG was then performed, and measurements were made at the same time in the same sequence as during the SHG before drug administration.

(b) Seven subjects were selected to receive practolol $(0.6 \mathrm{mg} / \mathrm{kg})$ which was given i.v. over a 2 -min period." The protocol for subsequent SHG and measurements after practolol were the same as that of propranolol group.

(c) Parasympathetic blockade was produced in 12 subjects by $2 \mathrm{mg}$ of atropine given as an i.v. bolus. $15 \mathrm{~min}$ later, base-line measurements and SHG were repeated.

(d) The last seven subjects who performed SHG after atropine were then given propranolol, and SHG was repeated after a $15-\mathrm{min}$ rest period. This regimen has been demonstrated to produce complete, or nearly complete cardiac autonomic blockage $(20,21)$. This phase of the protocol, i.e. blockade with both propranolol and atropine, was added after it appeared from analysis of the early results that atropine did not abolish the heart rate response to SHG.

(e) Heart rates were counted for 30-s intervals, e.g., heart rate at $1 \mathrm{~min}$ after onset of SHG was counted between 45 and $75 \mathrm{~s}$. In four subjects, recordings at paper speed of $75 \mathrm{~mm} / \mathrm{s}$, with $40 \mathrm{~ms}$ time lines, were made during the onset of SHG. The R-R intervals of the three beats immediately before and after the onset of SHG were measured in these patients.

Measurements and calculations were made as follows: base-line cardiac outputs were determined in duplicate, and single measurements were made during exercise; arterial pressure was measured directly from the brachial artery tracing, and the mean pressures were determined by electronic damping; systolic mean pressures were determined by planimetry; left ventricular ejection time (LVET) was measured as the average interval from the sharp upstroke to the incisura of five carotid pulse complexes. Left ventricular ejection time index (LVETI) was calculated from the regression equation of Weissler and Garrard (22), LVETI $=\mathrm{LVET}+1.7 \times$ heart rate. Preejection period (PEP) was calculated as the difference between the $Q$ wave of the electrocardiogram and the aortic closure sound ( $Q-A_{2}$ interval) and LVET. SVR was derived from the formula, (mean BA pressure $\times 1.33 \times 60$ ) /cardiac output, and the result was expressed in dyn-s- $\mathrm{cm}^{-5}$. The product of heart rate, systolic mean pressure, and ejection time was expressed as tension-time index. The statistical significance of the changes during SHG was determined by the method of paired and grouped means using the $t$ test. $P$ values $<0.05$ were regarded as significant (23).

t This dosage of propranolol has been shown to reduce the effectiveness of infused isoproterenol by approximately $90 \%$ (16).

${ }^{5}$ This dose of practolol has minimum effects on resting cardiac hemodynamics in normal subjects, but blocks the chronotropic effects of an isoproterenol infusion (0.025 $\mathrm{mg} / \mathrm{kg} / \mathrm{min}$ ) by approximately $75 \%$ (17). The dose-response curve of practolol as a blocker of catecholamine infusion and exercise tachycardia is quite flat between 0.6 and $1.2 \mathrm{mg} / \mathrm{kg}(18,19)$.

Autonomic Mechanisms in Isometric Exercises 
TABLE I

Effects of Handgrip before Drug Interventions

\begin{tabular}{|c|c|c|c|c|c|c|c|c|c|c|c|}
\hline & \multirow{2}{*}{$\begin{array}{l}\text { Heart } \\
\text { rate* }\end{array}$} & \multirow{2}{*}{$\begin{array}{l}\text { Cardiac } \\
\text { output* }\end{array}$} & \multirow{2}{*}{$\begin{array}{l}\text { Stroke } \\
\text { volume* }\end{array}$} & \multicolumn{3}{|c|}{ Arterial pressure* } & \multirow[b]{2}{*}{ SVR* } & \multirow[b]{2}{*}{ PEP } & \multirow[b]{2}{*}{ LVET $\ddagger$} & \multirow[b]{2}{*}{ LVETIf } & \multirow{2}{*}{$\begin{array}{c}\text { Rate } \\
\text { of LV } \ddagger \\
\text { ejection }\end{array}$} \\
\hline & & & & Systolic & Diastolic & Mean & & & & & \\
\hline$n=26$ & beats/min & liters $/ \min$ & $m l$ & & $m m \mathrm{Hg}$ & & $d y n-s-c m$ & $m s$ & $m s$ & $m s$ & $c c / s$ \\
\hline Rest & $65 \pm 1.8$ & $5.79 \pm 0.23$ & $89 \pm 3.2$ & $139 \pm 3.3$ & $72 \pm 1.3$ & $93 \pm 1.9$ & $1,338 \pm 50.2$ & $101 \pm 1.8$ & $302 \pm 3.4$ & $412 \pm 2.2$ & $289 \pm 9.3$ \\
\hline Handgrip & $\begin{array}{c}82 \pm 2.1 \\
+17 \pm 2.11\end{array}$ & $\begin{array}{r}7.10 \pm 0.31 \\
+1.31 \pm 0.23\end{array}$ & $\begin{array}{r}88 \pm 3.2 \\
-1 \pm 2.1\end{array}$ & $\begin{array}{r}166 \pm 5.3 \\
+27 \pm 3.6\end{array}$ & $\begin{array}{r}98 \pm 3.5 \\
+26 \pm 3.0\end{array}$ & $\begin{array}{r}121 \pm 3.8 \\
+28 \pm 3.3\end{array}$ & $\begin{array}{r}1,404 \pm 56.0 \\
+62 \pm 39.4\end{array}$ & $\begin{array}{l}100 \pm 2.4 \\
-1 \pm 2.2\end{array}$ & $\begin{array}{r}294 \pm 4.8 \\
-8 \pm 3.2\end{array}$ & $\begin{array}{r}431 \pm 3.4 \\
+19 \pm 3.4\end{array}$ & $\begin{aligned} 288 & \pm 10.2 \\
-1.2 & \pm 4.9\end{aligned}$ \\
\hline $\begin{array}{l}P \text { values } \\
\text { Rest vs. } \\
\text { Handgrip }\end{array}$ & $<0.001$ & $<0.001$ & $>0.5$ & $<0.001$ & $<0.001$ & $<0.001$ & $>0.1$ & $>0.5$ & $<0.025$ & $<0.001$ & $>0.2$ \\
\hline
\end{tabular}

$* n=26$.

$\ddagger n=22$.

\section{RESULTS}

All subjects noted forearm discomfort during the last minute of contraction, but were able to sustain $30 \%$ maximal voluntary contraction until studies were completed. Heart rate, blood pressure, and systolic time intervals returned to base-line values within 1-2 $\mathrm{min}$. Cardiac output also returned to base-line values before repeat SHG.

Responses to SHG before drug intervention (Table $I)$. The heart rate increased by $17 \pm 2.1$ (SE) beats/

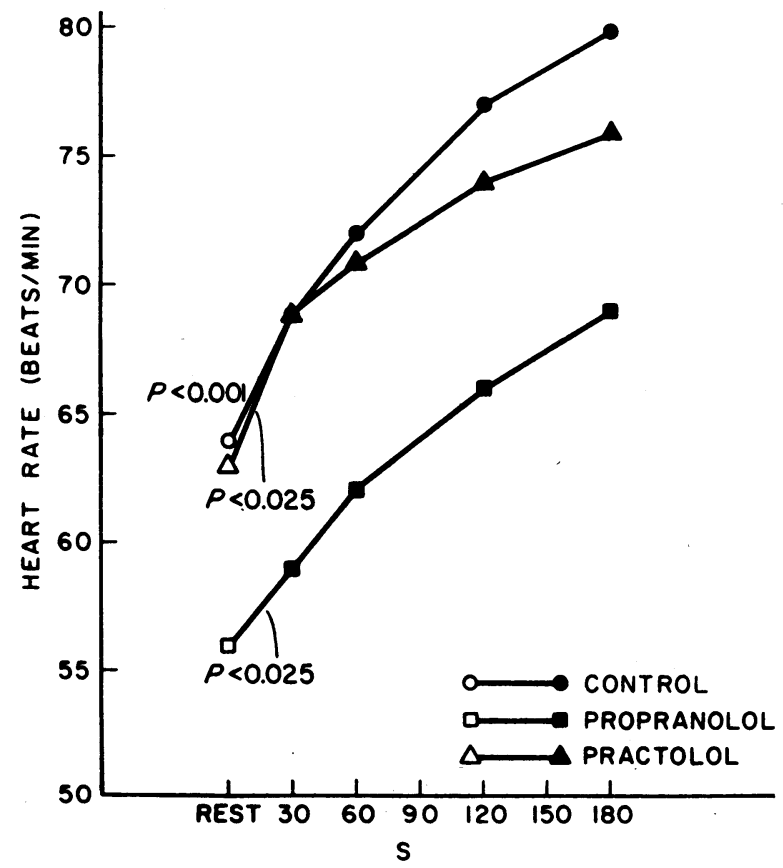

FIGURE 1 Effect of beta adrenergic blockade on the timed heart rate response to SHG. Propranolol lowers the resting rate, but, when used alone during handgrip, neither it nor practolol alters the heart rate response curve. $P$ values refer to difference between the heart rate at rest and $30 \mathrm{~s}$ after the onset of SHG. min. The time-course of this response is plotted in Figs. 1 and 2. At 30,60, 120, and $180 \mathrm{~s}$ there was an average increase of $6,8,14$, and 18 beats $/ \mathrm{min}$, respectively. In the four subjects in whom it was measured, shortening of the R-R interval by $59 \mathrm{~ms}$ occurred during the first three beats after initiation of exercise (Table II). Cardiac output rose by $1.31 \pm 0.23$ liter/ min without a change in stroke volume. There were increases in systolic (27 $\mathrm{mm} \mathrm{Hg}$ ), diastolic (26 mm $\mathrm{Hg}$ ), and mean $(28 \mathrm{~mm} \mathrm{Hg})$ arterial pressure. Calculated SVR did not change significantly. PEP was

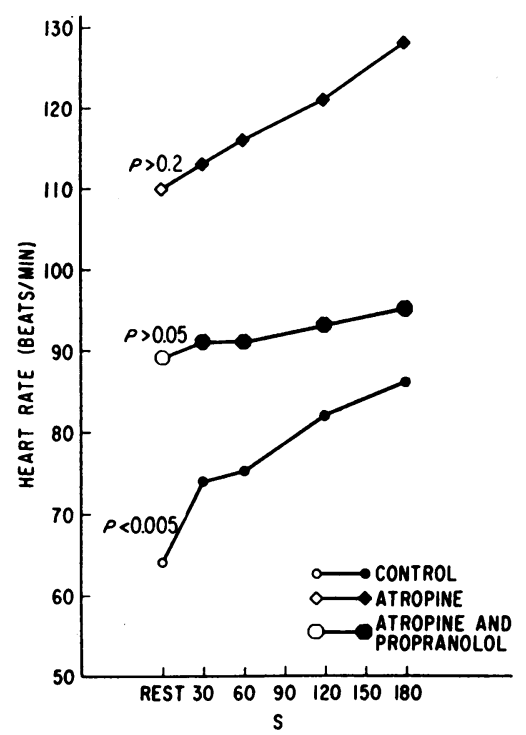

FIgURE 2 Effects of atropine and total autonomic blockade on the heart rate response to SHG in matched subjects $(n=7)$. After atropinization, the initial $30 \mathrm{~s}$ of SHG does not increase the heart rate $(P>0.2)$. However, the remainder of the rate response curve is similar to that of SHG before atropine. Combined autonomic blockade prevents an increase in heart rate throughout the entire period of SHG. The rate increase during SHG after atropine is therefore demonstrated to be of sympathetic origin. 
TABLE II

Effect of Atropine on the Immediate Heart Rate Response to SHG

\begin{tabular}{lrrr}
\hline & $\begin{array}{c}\text { Before } \\
\text { drugs }\end{array}$ & $\begin{array}{c}\text { After } \\
\text { atropine }\end{array}$ & $\begin{array}{r}\text { Atropine } \\
\text { + propranolol }\end{array}$ \\
\hline Mean cardiac cycle length, $m s$ & & & \\
Last three beats during rest & 959 & 552 & 676 \\
First three beats during handgrip & 900 & 548 & 676 \\
$\quad$ Change & 59 & 4 & 0 \\
\hline
\end{tabular}

unchanged. Although LVET decreased by $8 \mathrm{~ms}$, LVETI increased by $19 \mathrm{~ms} \pm 3.4$. This index is used to "correct" ejection time for heart rate by extrapolation to zero heart rate. Normal values are $413 \pm 10$ (22). Tensiontime index increased during SHG by $1160 \pm 20 \mathrm{~mm} \mathrm{Hg}$ $\mathrm{s} / \mathrm{min}$, largely as a result of increased heart rate and systolic arterial pressure.

Effects of propranolol (Table III). Propranolol affected resting base-line values in the following manner: heart rate and cardiac output decreased by 6 beats/

TABLE III

Effects of Propranolol

\begin{tabular}{|c|c|c|c|c|c|c|c|c|c|c|c|}
\hline \multirow[b]{2}{*}{ Subject } & \multirow{2}{*}{$\begin{array}{l}\text { Heart } \\
\text { rate }\end{array}$} & \multirow{2}{*}{$\begin{array}{l}\text { Cardiac } \\
\text { output }\end{array}$} & \multirow{2}{*}{$\begin{array}{l}\text { Stroke } \\
\text { volume }\end{array}$} & \multicolumn{3}{|c|}{ Arterial pressure } & \multirow[b]{2}{*}{ SVR } & \multirow[b]{2}{*}{ PEP } & \multirow[b]{2}{*}{ LVET } & \multirow[b]{2}{*}{ LVETI } & \multirow{2}{*}{$\begin{array}{c}\text { Rate } \\
\text { of LV } \\
\text { ejection }\end{array}$} \\
\hline & & & & Systolic & Diastolic & Mean & & & & & \\
\hline & beats/min & liters/min & $m l$ & & $m m \mathrm{Hg}$ & & $d y n-s-c m^{-b}$ & $m s$ & $m s$ & $m s$ & $c c / s$ \\
\hline \multicolumn{12}{|l|}{ S. C. } \\
\hline Rest & 80 & 5.91 & 74 & 115 & 59 & 80 & 1,081 & 77 & 271 & 407 & 273 \\
\hline Rest-P & 69 & 4.55 & 66 & 115 & 65 & 80 & 1,405 & 77 & 303 & 420 & 218 \\
\hline SHG & 82 & 4.40 & 54 & 162 & 103 & 123 & 2,234 & 112 & 288 & 427 & 188 \\
\hline \multicolumn{12}{|l|}{ LSch. } \\
\hline Rest & 63 & 7.06 & 112 & 140 & 66 & 87 & 985 & 102 & 325 & 432 & 345 \\
\hline Rest-P & 55 & 6.21 & 113 & 134 & 66 & 87 & 1,120 & 116 & 329 & 422 & 343 \\
\hline SHG & 66 & 5.64 & 85 & 157 & 92 & 116 & 1,644 & 127 & 316 & 428 & 269 \\
\hline \multicolumn{12}{|l|}{ B. S. } \\
\hline Rest & 56 & 5.66 & 101 & 134 & 77 & 99 & 1,398 & 104 & 335 & 430 & 301 \\
\hline Rest-P & 49 & 5.04 & 103 & 126 & 72 & 97 & 1,538 & 110 & 342 & 425 & 301 \\
\hline SHG & 58 & 5.05 & 87 & 144 & 89 & 111 & 1.757 & 118 & 329 & 428 & 264 \\
\hline \multicolumn{12}{|l|}{ W. M. } \\
\hline Rest & 65 & 6.90 & 106 & 127 & 62 & 81 & 938 & 100 & 298 & 447 & 356 \\
\hline Rest-P & 62 & 6.21 & 100 & 119 & 65 & 83 & 1,068 & 107 & 301 & 417 & 332 \\
\hline SHG & 70 & 7.10 & 100 & 144 & 87 & 110 & 1,238 & 115 & 315 & 426 & 317 \\
\hline \multicolumn{12}{|l|}{ L. S. } \\
\hline Rest & 62 & 5.43 & 88 & 134 & 76 & 97 & 1,427 & 106 & 304 & 409 & 289 \\
\hline Rest-P & 62 & 5.14 & 83 & 134 & 78 & 95 & 1,477 & 108 & 308 & 413 & 269 \\
\hline SHG & 79 & 5.38 & 68 & 173 & 105 & 124 & 1,842 & 111 & 292 & 426 & 233 \\
\hline \multicolumn{12}{|l|}{ J. R. } \\
\hline Rest & 55 & 4.66 & 85 & 117 & 66 & 90 & 1,544 & 109 & 325 & 419 & 262 \\
\hline Rest-P & 53 & 4.24 & 80 & 112 & 67 & 89 & 1.678 & 113 & 318 & 408 & 252 \\
\hline SHG & 65 & 4.98 & 77 & 137 & 83 & 108 & 1.733 & 116 & 309 & 420 & 249 \\
\hline \multicolumn{12}{|l|}{ C. $\mathbf{M}$. } \\
\hline Rest & 51 & 5.29 & 104 & 123 & 60 & 81 & 1.224 & 106 & 316 & 403 & 329 \\
\hline Rest-P & 43 & 3.56 & 85 & 119 & 60 & 79 & 1,774 & 104 & 333 & 406 & 249 \\
\hline SHG & 62 & 5.36 & 86 & 169 & 94 & 116 & 1.730 & 117 & 324 & 429 & 265 \\
\hline \multicolumn{12}{|l|}{ Means } \\
\hline Rest & $62 \pm 4^{*}$ & $5.84 \pm 0.33$ & $96 \pm 5$ & $127 \pm 4$ & $67 \pm 3$ & $88 \pm 3$ & $1,228 \pm 89$ & $101 \pm 4$ & $311 \pm 8$ & $421 \pm 6$ & $308 \pm 13$ \\
\hline Rest-P & $56 \pm 3$ & $4.99 \pm 0.37$ & $91 \pm 6$ & $123 \pm 3$ & $68 \pm 2$ & $87 \pm 3$ & $1.437 \pm 100$ & $105 \pm 5$ & $319 \pm 6$ & $416 \pm 3$ & $281 \pm 16$ \\
\hline SHG & $69 \pm 3$ & $5.42 \pm 0.32$ & $80 \pm 6$ & $155 \pm 3$ & $93 \pm 3$ & $115 \pm 2$ & $1.740 \pm 111$ & $117 \pm 2$ & $310 \pm 6$ & $426 \pm 1$ & $254 \pm 14$ \\
\hline \multicolumn{12}{|l|}{$P$ values } \\
\hline Rest vs. Rest-P & $<0.01$ & $<0.005$ & $>0.05$ & $<0.025$ & $>0.40$ & $>0.20$ & $<0.025$ & $>0.05$ & $>0.10$ & $>0.2$ & $>0.05$ \\
\hline Rest-P vs. SHG & $<0.025$ & $>0.20$ & $>0.05$ & $<0.001$ & $<0.001$ & $<0.001$ & $<0.05$ & $<0.05$ & $>0.10$ & $<0.01$ & $>0.05$ \\
\hline
\end{tabular}

Abbreviations: Rest-P = resting values after propranolol; SHG = values during handgrip after propranolol.

- SE. 
TABLE IV

Effects of Practolol

\begin{tabular}{|c|c|c|c|c|c|c|c|c|c|c|c|}
\hline \multirow[b]{2}{*}{ Subject } & \multirow{2}{*}{$\begin{array}{l}\text { Heart } \\
\text { rate }\end{array}$} & \multirow{2}{*}{$\begin{array}{l}\text { Cardiac } \\
\text { output }\end{array}$} & \multirow{2}{*}{$\begin{array}{l}\text { Stroke } \\
\text { volume }\end{array}$} & \multicolumn{3}{|c|}{ Arterial pressure } & \multirow[b]{2}{*}{ SVR } & \multirow[b]{2}{*}{ PEP } & \multirow[b]{2}{*}{ LVET } & \multirow[b]{2}{*}{ LVETI } & \multirow{2}{*}{$\begin{array}{c}\text { Rate } \\
\text { of LV } \\
\text { ejection }\end{array}$} \\
\hline & & & & Systolic & Diastolic & Mean & & & & & \\
\hline & beats/min & liters/min & $m l$ & & $m m H g$ & & $d y n-s-c m^{-5}$ & $m s$ & $m s$ & $m s$ & $c c / s$ \\
\hline \multicolumn{12}{|l|}{ C. $\mathbf{M}$. } \\
\hline Rest & 61 & 4.56 & 75 & 137 & 62 & 82 & 1,437 & 110 & 316 & 420 & 237 \\
\hline Rest-Pc & 50 & 3.63 & 73 & 138 & 64 & 83 & 1,827 & 111 & 315 & 400 & 232 \\
\hline SHG & 62 & 4.34 & 70 & 184 & 101 & 129 & 2,357 & 120 & 318 & 423 & 220 \\
\hline \multicolumn{12}{|l|}{ L. S. } \\
\hline Rest & 65 & 4.65 & 72 & 129 & 74 & 98 & 1,684 & 112 & 317 & 428 & 227 \\
\hline Rest-Pc & 68 & 4.52 & 66 & 129 & 76 & 96 & 1,697 & 114 & 312 & 428 & 212 \\
\hline SHG & 80 & 5.41 & 68 & 159 & 98 & 122 & 1,802 & 112 & 318 & 434 & 214 \\
\hline \multicolumn{12}{|l|}{ S. C. } \\
\hline Rest & 78 & 5.91 & 76 & 107 & 69 & 83 & 1,122 & 100 & 281 & 414 & 270 \\
\hline Rest-Pc & 79 & 5.12 & 65 & 106 & 68 & 81 & 1,264 & 101 & 278 & 412 & 234 \\
\hline SHG & 84 & 5.65 & 67 & 120 & 80 & 98 & 1,386 & 99 & 287 & 430 & 233 \\
\hline \multicolumn{12}{|l|}{ W. M. } \\
\hline Rest & 55 & 4.74 & 86 & 115 & 57 & 77 & 1,298 & 107 & 298 & 392 & 289 \\
\hline Rest-Pc & 59 & 4.44 & 75 & 119 & 67 & 81 & 1,458 & 110 & 295 & 395 & 254 \\
\hline SHG & 72 & 4.64 & 67 & 156 & 91 & 92 & 1,585 & 115 & 319 & 436 & 210 \\
\hline \multicolumn{12}{|l|}{ S. J. } \\
\hline Rest & 66 & 5.38 & 82 & 118 & 69 & 94 & 1,396 & 98 & 308 & 420 & 266 \\
\hline Rest-Pc & 63 & 5.03 & 80 & 129 & 80 & 100 & 1,589 & 92 & 317 & 424 & 252 \\
\hline SHG & 70 & 4.96 & 71 & 165 & 108 & 129 & 2,079 & 95 & 317 & 436 & 224 \\
\hline \multicolumn{12}{|l|}{ M. A. } \\
\hline Rest & 67 & 5.45 & 81 & 147 & 84 & 104 & 1,525 & 117 & 297 & 411 & 273 \\
\hline Rest-Pc & 68 & 5.21 & 77 & 143 & 84 & 98 & 1,503 & 112 & 273 & 389 & 282 \\
\hline SHG & 88 & 5.02 & 57 & 118 & 110 & 135 & 2,149 & 114 & 276 & 426 & 206 \\
\hline \multicolumn{12}{|l|}{ T. T. } \\
\hline Rest & 52 & 4.41 & 85 & 130 & 72 & 88 & 1,595 & 100 & 320 & 408 & 266 \\
\hline Rest-Pc & 54 & 4.62 & 86 & 130 & 76 & 90 & 1,557 & 104 & 305 & 397 & 282 \\
\hline SHG & 78 & 6.66 & 85 & 190 & 122 & 144 & 1,728 & 108 & 306 & 439 & 278 \\
\hline \multicolumn{12}{|l|}{ Mean } \\
\hline Rest & $63 \pm 3^{*}$ & $5.01 \pm 0.21$ & $80 \pm 2$ & $126 \pm 5$ & $70 \pm 3$ & $89 \pm 4$ & $1,437 \pm 71$ & $106 \pm 3$ & $305 \pm 5$ & $413 \pm 4$ & $261 \pm 8$ \\
\hline Rest-Pc & $63 \pm 4$ & $4.65 \pm 0.21$ & $75 \pm 3$ & $128 \pm 5$ & $74 \pm 3$ & $90 \pm 3$ & $1,556 \pm 68$ & $106 \pm 3$ & $299 \pm 7$ & $406 \pm 6$ & $250 \pm 9$ \\
\hline SHG & $76 \pm 4$ & $5.24 \pm 0.29$ & $69 \pm 3$ & $165 \pm 9$ & $101 \pm 5$ & $121 \pm 7$ & $1,869 \pm 129$ & $109 \pm 3$ & $306 \pm 7$ & $432 \pm 2$ & $226 \pm 9$ \\
\hline \multicolumn{12}{|l|}{$P$ values } \\
\hline Rest vs. Rest-Pc & $>0.5$ & $>0.05$ & $<0.05$ & $>0.4$ & $>0.05$ & $>0.5$ & $>0.05$ & $>0.5$ & $>0.1$ & $>0.1$ & $>0.2$ \\
\hline Rest-Pc vs. SHG & $<0.005$ & $>0.05$ & $>0.1$ & $<0.001$ & $<0.001$ & $<0.005$ & $<0.01$ & $>0.1$ & $>0.05$ & $<0.005$ & $>0.05$ \\
\hline
\end{tabular}

Abbreviations: Rest-Pc = resting value after practolol $;$ SHG $=$ value during handgrip after practolol.

* SE.

$\min$ and $850 \mathrm{ml} / \mathrm{min}$, respectively; there was a $4-\mathrm{mm}$ $\mathrm{Hg}$ drop in systolic pressure, but no change in diastolic or mean arterial pressure; there was an increase in calculated SVR; stroke volume decreased in only five of seven subjects, a result indicating no significant change for group $P>0.05$; propranolol did not affect resting systolic time intervals.

After propranolol, SHG increased heart rate by 13 beats/min, the time-course being similar to that observed before propranolol (Fig. 1). Increases in systolic, diastolic, and mean arterial pressures were similar to those obtained before propranolol, but cardiac output did not increase significantly $(P>0.20)$. Therefore, calculated total SVR increased from 1,437 to 1,740 dyn-s-cm ${ }^{-5}$, a response which differed $(P<0.001)$ from that which occurred during SHG before propranolol. PEP increased by $12 \mathrm{~ms}(P<0.05)$. Mean rate of left ventricular ejection did not change significantly. Tension-time index increased by $998 \mathrm{~mm} \mathrm{Hg} \mathrm{s/min,} \mathrm{similar}$ to the response before propranolol.

Effects of practolol (Table IV). Practolol, in contrast to propranolol, had no effect on resting heart rate. The tendency toward reduction in cardiac output and stroke volume was of borderline statistical significance. Arterial pressure was unchanged.

SHG after practolol caused a heart rate increase of 13 beats/min after a time-course similar to that during control SHG (Fig. 1). Although cardiac output increased slightly in five subjects, the change for the group was not significant $(P>0.05)$. Mean ar- 
terial pressure increased by $31 \mathrm{~mm} \mathrm{Hg}$ and, as after propranolol, calculated SVR increased. The increase in resistance differed from the response during control SHG $(P<0.05)$. LVETI increased by $26 \mathrm{~ms}$, but PEP did not change. Mean rate of ejection decreased in six of seven subjects $(P>0.05)$. The rise in tension-time index, $1,367 \mathrm{~mm} \mathrm{Hg} \mathrm{s} / \mathrm{min}$, was similar to control SHG.

Effects of atropine (Table $V$ ). Atropine altered base-line resting values, as shown in Table V. Heart rate increased to 115 beats $/ \mathrm{min}$, and cardiac output rose to $7.58 \mathrm{liter} / \mathrm{min}$. Stroke volume dropped $28 \mathrm{ml}$. Arterial diastolic pressure increased from 75 to $90 \mathrm{~mm}$ $\mathrm{Hg}$.

During SHG after atropine, heart rate increased by 12 beats $/ \min (P<0.005)$. The time-course of this response in matched subjects is shown in Fig. 2. There was now blunting of the early (30 s) heart rate response (increase of 2 beats, vs. 10 beats during control SHG), after which the heart rate response curve was similar to that observed during control SHG. The effect of atropine on the immediate rate response to SHG is shown for four subjects in Table II. Only slight shortening of the average cardiac cycle length (4 ms) is observed during the first three beats after the onset of SHG. Cardiac output increased by $650 \mathrm{ml}$ $(P<0.005)$. The increase in arterial pressure was similar to that observed before atropine administration. Calculated total SVR increased in 10 of 12 subjects $(P>0.05)$. Ejection time index increased by $6 \mathrm{~ms}$ $(P<0.001)$. There was a statistically significant but small (3 ms) shortening of PEP.

Effects of atropine plus propranolol (Table $V$ ). After combined blockade, the heart rate averaged 89 beats/min. Cardiac output measured $7.02 \mathrm{liter} / \mathrm{min}$, down $56 \mathrm{ml}$ from that after atropine alone. Arterial diastolic pressure remained elevated, as after atropine alone.

During SHG after combined blockade, there was no significant increase in either heart rate or cardiac output. Systolic, diastolic, and mean arterial pressure rose by 16,20 , and $22 \mathrm{~mm} \mathrm{Hg}$, respectively. Calculated SVR increased by 214 dyn-s-cm ${ }^{-5}$.

Comparison before and during drug intervention. A comparison of the changes in cardiac output, arterial pressure, and SVR during SHG, before and during drug intervention, is shown in Fig. 3. Before drug interventions, the pressor response was accompanied by an increase in cardiac output. A rise in cardiac output did not occur during SHG after propranolol, practolol, or combined propranolol-atropine. The pressor response resulted from an increase in SVR.

The rise in tension-time index during SHG is shown to be unaltered by beta adrenergic receptor blockade with either propranolol or practolol (Fig. 4). The effects of SHG on systolic time intervals are shown in Fig. 5. PEP is shown to be prolonged during SHG only after propranolol. There was a consistent increase in LVETI during SHG before and after drug interventions, except after combined blockade. LVET shortened during control SHG and SHG after atropine. There were no significant changes in right atrial pressure during SHG. Atropine decreased resting right atrial pressure by approximately $4 \mathrm{~mm} \mathrm{Hg}$, usually to zero.

\section{DISCUSSION}

Heart rate response to handgrip. The magnitude of the chronotropic response to SHG is related primarily to two variables. The first, intensity of contraction of the muscle group, determines the relative importance of the second, which is the duration of the contraction. Therefore, when SHG is sustained at $15 \%$ or less of maximal voluntary contraction, a steady state is reached quickly, and the contraction may be sustained for long periods without fatigue or further hemodynamic changes. In contrast, the size of the contracting muscle group is relatively unimportant $(1,24,25)$. At the higher levels of exercise performed in the present study, a steady state is not reached. The duration of the contraction becomes a critical determinant of the magnitude, and possibly the mechanism of the heart rate response.

Withdrawal of the vagal tone is the autonomic effector mechanism to which the development of tachycardia during SHG is generally attributed $(6,12)$. Consistent with this view is the short latency period $(0.5 \mathrm{~s})$ which has been reported to occur between the onset of SHG and the onset of tachycardia. Immediate onset of tachycardia was also found in the present study during control SHG but not after atropinization. On the other hand, there is reported to be a longer latency period (3-6 s) between sympathetic stimulation and cardiac acceleration (13). It is unlikely, therefore, that sympathetic stimulation initiates the heart rate response to SHG. Atropinization was found by Freyschuss to block the tachycardia response during handgrip which was held for $45 \mathrm{~s}$ (26). There was also blockade of the 30-s heart rate response in the present study after atropine. These data are in agreement with the previous studies demonstrating that withdrawal of vagal tone initiates the tachycardia during SHG. On the other hand, our data show that a mechanism in addition to vagal withdrawal is potentially operative in producing tachycardia during the last $2.5 \mathrm{~min}$ of SHG, since atropine did not block the heart rate response during this period (Fig. 2). It would appear, then, that withdrawal of vagal tone was the first mechanism to be utilized in the heart rate response to SHG and that the sympathetic effector response occurred after the first mechanism had been uti- 
TABLE V

Effects of Atropine and Combined Autonomic Blockade

\begin{tabular}{|c|c|c|c|c|c|c|c|c|c|c|c|}
\hline \multirow[b]{2}{*}{ Subject } & \multirow{2}{*}{$\begin{array}{l}\text { Heart } \\
\text { rate }\end{array}$} & \multirow{2}{*}{$\begin{array}{l}\text { Cardiac } \\
\text { output }\end{array}$} & \multirow{2}{*}{$\begin{array}{l}\text { Stroke } \\
\text { volume }\end{array}$} & \multicolumn{3}{|c|}{ Arterial pressure } & \multirow[b]{2}{*}{ SVR } & \multirow[b]{2}{*}{ PEP } & \multirow[b]{2}{*}{ LVET } & \multirow[b]{2}{*}{ LVETI } & \multirow{2}{*}{$\begin{array}{c}\text { Rate } \\
\text { of } L V \\
\text { ejection }\end{array}$} \\
\hline & & & & Systolic & Diastolic & Mean & & & & & \\
\hline & beats/min & liters $/ \min$ & $m l$ & & $m m \mathrm{Hg}$ & & $d y n-s-c m^{-b}$ & $m s$ & $m s$ & $m s$ & $c c / s$ \\
\hline Rest & 70 & 5.05 & 72 & 140 & 75 & \multicolumn{6}{|c|}{$\begin{array}{l}\text { L. S. } \\
\text { Rest }\end{array}$} \\
\hline Rest-A & 108 & 5.12 & 47 & 145 & 90 & $\begin{array}{l}100 \\
110\end{array}$ & $\begin{array}{l}1,583 \\
1,717\end{array}$ & 98 & 290 & 409 & 248 \\
\hline SHG & 112 & 4.57 & 41 & 160 & 115 & 135 & $\begin{array}{l}1,717 \\
2,360\end{array}$ & 107 & 230 & 412 & 204 \\
\hline \multirow{2}{*}{\multicolumn{12}{|c|}{ T. H. }} \\
\hline Rest & 72 & 5.67 & 79 & 137 & 63 & 90 & 1.269 & & & & \\
\hline Rest-A & 120 & 6.29 & 53 & 122 & 76 & 95 & 1,207 & 109 & $\begin{array}{l}286 \\
221\end{array}$ & $\begin{array}{l}414 \\
431\end{array}$ & $\begin{array}{l}276 \\
231\end{array}$ \\
\hline SHG & 123 & 7.14 & 58 & 166 & 106 & 120 & 1,343 & 104 & 225 & 433 & 257 \\
\hline \multicolumn{12}{|l|}{ GL } \\
\hline Rest & 53 & 6.03 & 115 & 177 & 80 & 97 & 1,287 & 90 & 306 & 400 & 376 \\
\hline Rest-A & 125 & 7.83 & 63 & 177 & 92 & 98 & 1,001 & 105 & 204 & 418 & 250 \\
\hline SHG & 126 & 8.47 & 67 & 195 & 115 & 127 & 1,200 & 99 & 206 & 425 & 248 \\
\hline \multicolumn{12}{|l|}{ R. C. } \\
\hline Rest & 78 & 7.75 & 99 & 151 & 73 & 101 & 1,042 & 105 & 284 & 413 & 349 \\
\hline Rest-A & 133 & 6.32 & 47 & 156 & 98 & 118 & 1,494 & 112 & 208 & 432 & 309 \\
\hline SHG & 138 & 9.62 & 70 & 183 & 110 & 133 & 1,105 & 106 & 198 & 436 & 325 \\
\hline J. H. & & & & & & & & & & & \\
\hline Rest & 72 & 5.40 & 75 & 160 & 77 & 100 & 1,480 & 114 & 297 & 409 & 253 \\
\hline Rest-A & 120 & 7.14 & 59 & 149 & 102 & 111 & 1,242 & 108 & 236 & 440 & 226 \\
\hline SHG & 130 & 7.81 & 59 & 177 & 110 & 137 & 1,402 & 104 & 235 & 449 & 353 \\
\hline A. $\mathbf{M}$. & & & & & & & & & & & \\
\hline Rest & 66 & 6.87 & 104 & 141 & 70 & 87 & 1,031 & 90 & 302 & 414 & 344 \\
\hline Rest-A & 117 & 7.43 & 64 & 126 & 74 & 91 & 980 & 92 & 240 & 429 & 267 \\
\hline SHG & 136 & 7.75 & 57 & 154 & 94 & 114 & 1,177 & 86 & 213 & 439 & 268 \\
\hline Rest-A + P & 84 & 6.43 & 77 & 134 & 70 & 88 & 1,095 & 112 & 281 & 419 & 274 \\
\hline HG & 87 & 5.96 & 68 & 142 & 90 & 107 & 1,436 & 109 & 279 & 418 & 244 \\
\hline W. H. & & & & & & & & & & & \\
\hline Rest & 63 & 4.96 & 79 & 126 & 70 & 81 & 1,306 & 100 & 289 & 401 & 273 \\
\hline Rest-A & 117 & 6.11 & 52 & 129 & 76 & 94 & 1,231 & 101 & 221 & 420 & 235 \\
\hline SHG & 120 & 5.72 & 48 & 160 & 100 & 116 & 1,622 & 96 & 222 & 424 & 216 \\
\hline Rest- $A+P$ & 90 & 4.51 & 50 & 123 & 76 & 94 & 1,667 & 129 & 251 & 407 & 199 \\
\hline HG & 87 & 4.80 & 55 & 144 & 100 & 120 & 2,000 & 129 & 253 & 404 & 217 \\
\hline J. F. & & & & & & & & & & & \\
\hline Rest & 36 & 5.35 & 95 & 161 & 74 & 90 & 1,346 & 111 & 298 & 392 & 319 \\
\hline Rest-A & 103 & 7.62 & 74 & 150 & 93 & 113 & 1,186 & 107 & 249 & 422 & 297 \\
\hline SHG & 132 & 9.08 & 69 & 160 & 106 & 121 & 1.066 & 97 & 221 & 425 & 312 \\
\hline Rest-A + P & 88 & 6.85 & 77 & 160 & 102 & 122 & 1,429 & 119 & 264 & 415 & 292 \\
\hline HG & 94 & 7.07 & 72 & 156 & 109 & 125 & 1,414 & 110 & 258 & 416 & 279 \\
\hline w. s. & & & & & & & & & & & \\
\hline Rest & 55 & 6.15 & 109 & 165 & 85 & 115 & 1,521 & 108 & 328 & 442 & 332 \\
\hline Rest-A & 90 & 8.32 & 92 & 175 & 90 & 115 & 1,106 & 114 & 266 & 439 & 345 \\
\hline SHG & 117 & 9.76 & 83 & 210 & 160 & 160 & 1,312 & 116 & 244 & 443 & 340 \\
\hline Rest-A + $\mathbf{P}$ & 76 & 7.32 & 76 & 170 & 90 & 115 & 1.256 & 126 & 300 & 429 & 253 \\
\hline HG & 84 & 7.48 & 89 & 205 & 130 & 155 & 1,658 & 130 & 288 & 431 & 309 \\
\hline T. T. & & & & & & & & & & & \\
\hline Rest & 51 & 4.46 & 87 & 160 & 80 & 100 & 1,794 & 119 & 311 & 398 & 279 \\
\hline Rest-A & 95 & 7.96 & 83 & 180 & 105 & 190 & 1,306 & 112 & 270 & 432 & 307 \\
\hline SHG & 111 & 8.02 & 72 & 215 & 130 & 160 & 1,596 & 118 & 254 & 443 & 283 \\
\hline Rest-A + P & 86 & 7.00 & 81 & 176 & 96 & 120 & 1,371 & 108 & 290 & 436 & 279 \\
\hline HG & 102 & 8.24 & 81 & 216 & 136 & 155 & 1,505 & 119 & 271 & 444 & 298 \\
\hline G. L. & & & & & & & & & & & \\
\hline Rest & 72 & 7.70 & 107 & 145 & 75 & 90 & 935 & & & & \\
\hline Rest-A & 135 & 11.94 & 88 & 165 & 90 & 115 & 770 & & & & \\
\hline SHG & 162 & 11.58 & 71 & 185 & 115 & 130 & 898 & & & & \\
\hline Rest-A + P & 108 & 9.11 & 84 & 170 & 100 & 120 & 1,054 & & & & \\
\hline HG & 123 & 9.30 & 76 & 170 & 110 & 125 & 1.075 & & & & \\
\hline
\end{tabular}


TABLE V-(Continued)

\begin{tabular}{|c|c|c|c|c|c|c|c|c|c|c|c|}
\hline \multirow[b]{2}{*}{ Subject } & \multirow{2}{*}{$\begin{array}{l}\text { Heart } \\
\text { rate }\end{array}$} & \multirow{2}{*}{$\begin{array}{l}\text { Cardiac } \\
\text { output }\end{array}$} & \multirow{2}{*}{$\begin{array}{l}\text { Stroke } \\
\text { volume }\end{array}$} & \multicolumn{3}{|c|}{ Arterial pressure } & \multirow[b]{2}{*}{ SVR } & \multirow[b]{2}{*}{ PEP } & \multirow[b]{2}{*}{ LVET } & \multirow[b]{2}{*}{ LVETI } & \multirow{2}{*}{$\begin{array}{c}\text { Rate } \\
\text { of LV } \\
\text { ejection }\end{array}$} \\
\hline & & & & Systolic & Diastolic & Mean & & & & & \\
\hline & beats/min & liters $/ \min$ & $m l$ & & $m m \mathrm{Hg}$ & & $d y n-s-c^{-b}$ & $m s$ & $m s$ & $m s$ & $c c / s$ \\
\hline \multicolumn{12}{|l|}{ G. H. } \\
\hline Rest & 84 & 9.10 & 108 & 150 & 75 & 100 & 879 & & & & \\
\hline Rest-A & 114 & 8.85 & 77 & 145 & 85 & 105 & 949 & & & & \\
\hline SHG & 120 & 9.34 & 78 & 150 & 90 & 115 & 985 & & & & \\
\hline Rest-A + P & 90 & 7.94 & 88 & 140 & 90 & 100 & 1,008 & & & & \\
\hline HG & 90 & 7.41 & 82 & 150 & 95 & 120 & 1,295 & & & & \\
\hline \multicolumn{12}{|l|}{ Means } \\
\hline Rest & $66 \pm 3^{*}$ & $6.21 \pm 0.40$ & $94 \pm 4$ & $151 \pm 4$ & $75 \pm 2$ & $96 \pm 3$ & $1,289 \pm 81$ & $104 \pm 3$ & $299 \pm 4$ & $409 \pm 4$ & $305 \pm 14$ \\
\hline Rest-A & $115 \pm 4$ & $7.58 \pm 0.50$ & $66 \pm 5$ & $152 \pm 6$ & $90 \pm 3$ & $108 \pm 3$ & $1,182 \pm 73$ & $107 \pm 2$ & $235 \pm 7$ & $427 \pm 3$ & $267 \pm 14$ \\
\hline SHG & $127 \pm 4$ & $8.23 \pm 0.54$ & $65 \pm 4$ & $176 \pm 6$ & $113 \pm 5$ & $131 \pm 5$ & $1,338 \pm 113$ & $104 \pm 3$ & $224 \pm 5$ & $433 \pm 4$ & $290 \pm 18$ \\
\hline Rest-A + P & $89 \pm 4$ & $7.02 \pm 0.53$ & $76 \pm 5$ & $153 \pm 8$ & $89 \pm 5$ & $108 \pm 5$ & $1,269 \pm 90$ & $118 \pm 4$ & $277 \pm 9$ & $421 \pm 5$ & $259 \pm 16$ \\
\hline HG & $95 \pm 5$ & $7.18 \pm 0.56$ & $75 \pm 4$ & $169 \pm 11$ & $109 \pm 7$ & $130 \pm 7$ & $1,483 \pm 110$ & $119 \pm 5$ & $270 \pm 7$ & $423 \pm 7$ & $270 \pm 17$ \\
\hline \multicolumn{12}{|l|}{$P$ values } \\
\hline Rest-A vs. SHG & $<0.005$ & $<0.05$ & $>0.4$ & $<0.001$ & $<0.001$ & $<0.001$ & $>0.05$ & $<0.05$ & $<0.01$ & $<0.001$ & $>0.5$ \\
\hline Rest-A + P vs. HG & $>0.05$ & $>0.4$ & $>0.5$ & $<0.05$ & $<0.01$ & $<0.01$ & $<0.025$ & $>0.5$ & $>0.1$ & $>0.4$ & $>0.5$ \\
\hline
\end{tabular}

Abbreviations: Rest-A = resting value after atropine; SHG = value during handgrip after atropine; Rest-A + P = resting value after atropine + propranolol; $H G=$ value during handgrip after atropine + propranolol.

* SE.

lized. It is important to note, however, that a normal heart rate response to SHG occurred without sympathetic stimulation, as was demonstrated during the beta adrenergic receptor blockade (Fig. 1). In this instance, the mechanism of vagal withdrawal was incompletely utilized, in that a lower heart rate was achieved during SHG than results from atropinization of a subject at rest (Figs. 1 and 2). Another potential mechanism for a positive chronotropic response is the reflex described by Blinks, i.e., heart rate increase resulting from in-

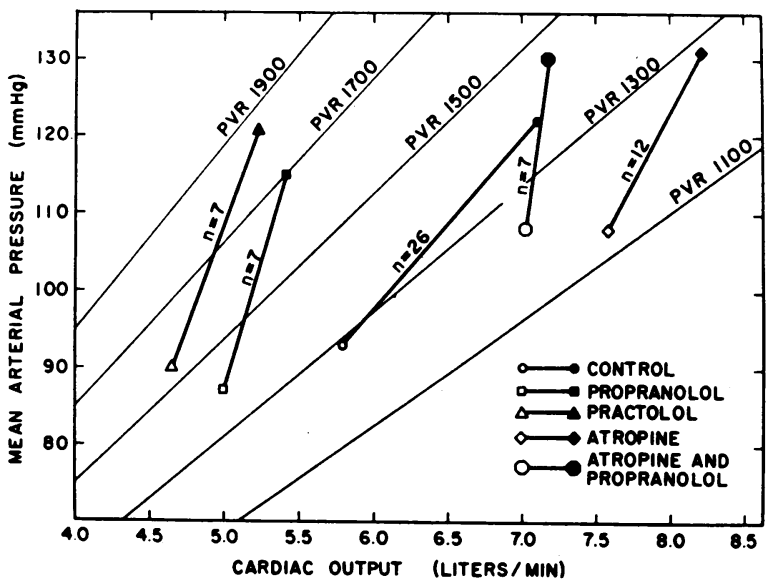

Figure 3 Hemodynamic responses to SHG. Before drugs and after atropine, there is a proportional rise in arterial pressure and cardiac output but no change in total peripheral vascular resistance (PVR). After propranolol, practolol, or combined autonomic blockade, there is a similar pressor response which occurs without a rise in cardiac output but results from increased resistance. Resistance is expressed in dyn-s- $\mathrm{cm}^{-5}$. creased venous return (27). That the tachycardia during SHG is not due to the Blinks reflex is evidenced by the effectiveness of combined autonomic blockade in preventing an increase in heart rate (Fig. 2).

The weight of evidence therefore points to a potential dual autonomic mechanism for heart rate control during SHG. Vagal withdrawal provides the early response, while sympathetic influence appears later after atropinization, or if needed, during severe stress. A dual mechanism for heart rate response has also been demonstrated during two other forms of stress, severe isotonic exercise and acute hypotension in which vagal withdrawal provides the early response with evidence of sympathetic stimulation occurring later $(28,29)$.

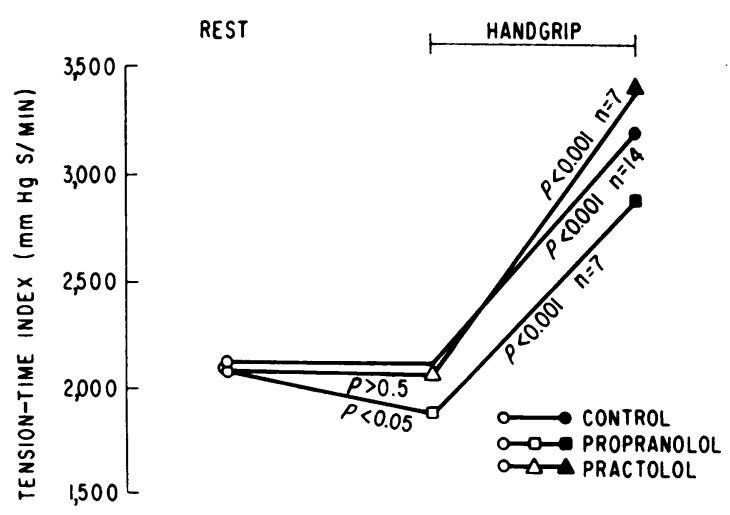

Figure 4 Effects of SHG on tension-time index. Propranolol decreased the resting value, but neither it nor practolol lessened the response as compared to that of control SHG $(P>0.4)$.

Autonomic Mechanisms in Isometric Exercises 


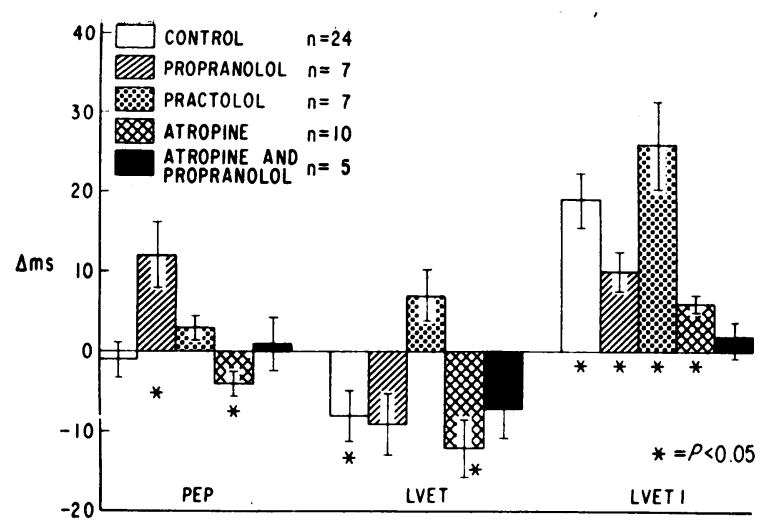

FIGURE 5 Effects of SHG on systolic time intervals. The LVETI (LVET corrected for heart rate) was consistently increased by SHG, except after combined blockade. Despite an increase in heart rate, SHG had little effect on LVET (uncorrected for heart rate). PEP was unchanged during control SHG. Prolongation of PEP after propranolol may reflect the cardiac depressant effect on this drug. The shortening observed during SHG after atropine may be related to adrenergic stimulation. The latter is also reflected by an increase in heart rate.

The pressor response to handgrip. A marked rise in arterial pressure is characteristically produced by SHG at $15 \%$ or greater of maximal contraction. The afferant mechanism by which contraction of even a small muscle group initiates and maintains the pressor response is still debated. There is evidence for both centrally and peripherally mediated reflexes $(12,30)$. In this study only the efferent mechanism was measured. During control SHG and after atropine, there is a concurrent rise in cardiac output and blood pressure. By application of the general formula, resistance $=$ pressure $/$ flow, it becomes apparent that calculated total SVR does not change and that the pressor response is in direct proportion to the increase in cardiac output. What changes occurred in peripheral vascular tone, as opposed to calculated resistance, are not clear, however, since the nature of the flow-pressure curve of the vascular bed under investigation was not known.

From the studies of others, several inferences can be made regarding the behavior of the resistance vessels during an increase in both flow and pressure. In this situation two responses may occur to decrease SVR: $(a)$ passive dilatation and $(b)$ reflex vasodilatation from baroceptor stimulation $(31,32)$. It has been suggested that the baroceptors are somehow inactivated during SHG (allowing tachycardia to occur in spite of an increase pressure and allowing a partial pressor response to occur during SHG in the presence of alpha adrenergic receptor blockade) $(1,26)$. On the other hand, an increase in perfusion pressure may act to increase vascular resistance over control values by the mechanism of autoregulation, which is basically independent of neural control (32). Because of changes in both pressure and flow during SHG, therefore, the role of sympathetic stimulation in producing the pressor response cannot be evaluated.

After propranolol, however, SHG did not increase cardiac output. The pressor response, equivalent to that of control SHG, was related to an increase in SVR, resulting most likely from sympathetic vasoconstriction. There are two plausible explanations as to how this may occur. MacDonald, Sapru, Taylor and Donald, who reported similar results during SHG, noted that propranolol may lead to unopposed vasoconstriction by virtue of its peripheral beta adrenergic blocking effect, which is manifested by an increase in vascular resistance of resting subjects (33). An alternative explanation suggests that SHG elicits vasoconstrictor activity which is unmasked or accentuated by the cardiac depressant effect of propranolol which prevents an increase in cardiac output from occurring during SHG (33). If the latter explanation is correct for the response to SHG after propranolol, one would expect a similar result following practolol, a cardioselective beta adrenergic receptor-blocking drug which depresses cardiac responses to sympathetic stimulation with the approximate effectiveness of propranolol (34-36). As illustrated in Fig. 3, the pressor response after practolol is similar to that after propranolol and is related to an increase in SVR with no significant increase in cardiac output. This demonstrates that vasoconstriction due to sympathetic stimulation, independent of peripheral beta adrenergic blockade, is an effective mechanism for raising blood pressure during SHG.

Reciprocal changes in resistance of vessels supplying exercising and nonexercising beds is not unique to SHG, but also occurs in isotonic exercise. During isotonic leg exercise, vasoconstriction is demonstrated in the forearm arteries, although there is a decrease in SVR (37). However, in isometric exercise, there is the added factor of inflow obstruction, caused by continuous mechanical compression of vessels supplying the exercising muscles (1). The marked rise in arterial pressure during SHG may be viewed as an obligatory response designed to improve flow to exercising muscle. It might be achieved by increasing cardiac output, autoregulation, inactivity of baroceptor vasodilator reflexes, sympathetic vasoconstriction, or a combination of these. The relative functional importance of vasoconstriction in the pressor response may depend, in part, on the ability of cardiac output to increase, as well as on individual variation in reactivity of the sympathetic vasoconstrictors. These factors may explain the increase in calculated peripheral resistance which occurs during SHG in some elderly persons and in patients with hypertensive heart disease $(2,8,10)$. 
Effects of SHG on left ventricular function. Systolic time intervals have been widely used as a noninvasive measure of left ventricular performance $(22,38)$. Excellent direct correlation between the PEP and the first derivative of left ventricular pressure rise $(\mathrm{d} p / \mathrm{d} t)$ has been shown experimentally (39-41). However, PEP is limited as a measure of left ventricular function, particularly because it is also affected by both the left ventricular end diastolic and systemic arterial pressure (42). Tachycardia, if due to adrenergic stimulation, but not to vagal withdrawal, also shortens PEP (43).

The present study showed no prolongation of PEP during SHG before drugs (Fig. 5), although previous reports are conflicting $(44,45)$. Recently, PEP was also found not to change during SHG in patients with primary myocardial and coronary heart disease (46). The prolongation of PEP during SHG after propranolol might be explained by failure of the sympathetically blocked heart to respond to an increased afterload and systemic arterial pressure by shifting in the normal manner to a higher ventricular function curve (47). If the ventricular function curve (contractility) does not change, as it may not in patients with heart disease, and if left ventricular end diastolic fiber length either increases or does not change, then prolongation of PEP directly reflects the increase in aortic valve opening pressure which occurs during SHG. On the other hand, the failure of PEP to change during control SHG and after practolol may mean simply that there is an increase in contractility or, less likely, in ventricular end diastolic fiber length, or both, to counterbalance the tendency that increased aortic pressure would have to prolong PEP (42). Of interest is the tendency of PEP to shorten during SHG after atropine, perhaps a reflection of the previous observation that sympathetic stimulation, as opposed to vagal withdrawal, is operative in bringing about tachycardia following atropinization.

During SHG the normal inverse relationship between heart rate and the duration of LVET was altered. This normal relationship, which exists at rest and during isotonic exercise, has been defined by regression equations (22). LVETI (ejection time extrapolated to zero heart rate) was normal at rest, but was significantly prolonged during SHG (Fig. 5). This is in contrast to the studies of Siegel, Gilbert, Nutter, Schlant, and Hurst, who found no change during SHG in a smaller number of subjects; and it also differs from the response of LVETI to isotonic exercise during which no change occurs (45).

The differing responses of LVETI to isotonic and isometric exercise may be explained, to a large extent, by the greater increases in systemic arterial pressure and in afterload which occur during isometric exercise. An acute increase in afterload has been shown experimentally by Shaver, Kroetz, Leonard, and Paley to decrease the rate of left ventricular ejection, independent of changes in either heart rate or stroke volume (48). In the present study, no change in the mean rate of left ventricular ejection occurred during SHG. In contrast, isotonic exercise, which primarily raises only the systolic arterial pressure, increases the mean rate of left ventricular ejection, resulting in a shortened LVET and no change in LVETI.

Of possible clinical relevance are the changes in tension time index during SHG and the effects of beta adrenergic receptor blockade on these changes, in contrast to their effect in isotonic exercise. During isotonic exercise, but not during SHG, beta adrenergic blockade attenuates the rise in tension-time index for a given exercise load $(17,49)$. During SHG beta adrenergic blockade has no effect on heart rate, systolic arterial pressure, and ejection time, which are incorporated into tension time index and which are major determinates of myocardial oxygen consumption. Although it does not include changes in myocardial contractility, tension time index or a modification thereof has been useful for predicting the onset of angina pectoris during isotonic exercise before and after antianginal drugs $(50,51)$. A major reason for their failure to lower tension-time index is that beta adrenergic-blocking drugs have no effect on the pressor response to handgrip in contrast to their attenuating effect during isotonic exercise. The question as to whether or not these drugs will provide equally effective protection against angina pectoris during isometric or combined exercise, as they do during isotonic exercise alone, requires clinical testing.

\section{ACKNOWLEDGMENTS}

We are grateful to Miss Mary Ann Scully, Miss Arlene Scarlatelli, Mrs. Minnie Flansbaum, Mrs. Pat Tripp, Mrs. Edna Palmer, Mrs. Wendy Harbaugh, and Mr. John Fabrizio for their assistance.

This study was supported by Grant 5TO1 HL 05678-07 from the National Institutes of Health.

\section{REFERENCES}

1. Lind, A. R., S. H. Taylor, P. W. Humphreys, B. M. Kennelly, and K. W. Donald. 1964. The circulatory effects of sustained voluntary muscle contraction. Clin. Sci. (Oxf.). $27: 229-244$.

2. Lind, A. R., and G. W. McNicol. 1967. Muscular factors which determine the cardiovascular responses to sustained and rhythmic exercise. Can. Med. Assoc. J. 96: 706-713.

3. Fisher, M. L., D. O. Nutter, W. Jacobs, and R. C. Schlant. 1973. Hemodynamic responses to isometric exercise handgrip in patients with heart disease. $\mathrm{Br}$. Heart J. 35 : 422-432.

4. Atkins, J. M., O. A. Matthews, G. Blomquist, C. B. Mullins, and J. D. Houston. 1971. Arrhythmias induced by isometric (handgrip) exercise and dynamic exercise. Clin. Res. 19: 303. (Abstr.)

Autonomic Mechanisms in Isometric Exercises 
5. Helfant, R. H., M. A. deVilla, and S. G. Meister. 1971. Effect of sustained isometric handgrip exercise on left ventricular performance. Circulation. 44: 982993.

6. Nutter, D. O., R. C. Schlant, and J. R. Hurst. 1972. Isometric exercise and the cardiovascular system. Mod. Concepts Cardiovasc. Dis. 41: 11-15.

7. Lind, A. R. 1970. Cardiovascular responses to static exercise. Circulation. 41: 173-176.

8. Tarazi, R. C., and H. P. Dustan. 1971. Beta adrenergic blockade and response to static exercise. Clin. Pharmacol. Ther. $72: 23$. (Abstr.)

9. Hoel, B. L., E. Lorentsen, and P. G. Lund-Larsen. 1970. Hemodynamic responses to sustained handgrip in patients with hypertension. Acta Med. Scand. 188: 491495.

10. Ewing, D. J., J. B. Irving, F. Kerr, and B. J. Kirby. 1973. Static exercise in untreated systemic hypertension. Br. Heart J. 35: 413-421.

11. Kivowitz, C., W. W. Parmley, R. Donoso, H. Marcus, W. Ganz, and H. J. C. Swan. 1971. Effects of isometric exercise on cardiac performance: the grip test. Circulation. 44: 994-1002.

12. Freyschuss, U. 1970. Cardiovascular adjustment to somatomotor activation: elicitation of increments in heart rate, aortic pressure and venomotor tone with the initiation of muscle contraction. Acta Physiol. Scand. Suppl. 342: 1-63.

13. Petro, J. K., A. P. Hollander, and L. N. Bouman. 1970. Instantaneous cardiac acceleration in man induced by a voluntary muscle contraction. J. Appl. Physiol. 29: 794-798.

14. Bruce, R. A., A. R. Lind, D. Franklin, A. L. Muir, H. R. MacDonald, G. W. McNicol, and K. W. Donald. 1968. The effects of digoxin on fatiguing static and dynamic exercise in man. Clin. Sci. (Oxf.). 34: 29-42.

15. Lind, A. R. 1959. Muscle fatigue and recovery from fatigue induced by sustained contractions. J. Physiol. (Lond.). 147 : 162-171.

16. Epstein, S. E., B. F. Robinson, R. L. Kahler, and E. Braunwald. 1965. Effects of beta-adrenergic blockade on the cardiac response to maximal and submaximal exercise in man. J. Clin. Invest. 44: 1745-1753.

17. Leon, D. F., M. E. Thompson, J. A. Shaver, and R. H. McDonald, Jr. 1972. Hemodynamic effects of practolol at rest and during exercise. Circulation. 45: 46-54.

18. Brick, I., K. J. Hutchison, D. G. McDevitt, I. C. Roddie, and R. G. Shanks. 1968. Comparison of the effects of I.C.I. 50172 and propranolol on the cardiovascular responses to adrenaline, isoprenaline and exercise. $\mathrm{Br}$. J. Pharmacol. 34 : 127-140.

19. Thompson, M. E., D. F. Leon, J. A. Shaver, and R. H. McDonald, Jr. 1970. Specific cardiac $\beta$-blockade. Pharmacologist. 12: 213. (Abstr.)

20. Jose, A. D. 1966. Effect of combined sympathetic and parasympathetic blockade on heart rate and cardiac function in man. Am. J. Cardiol. 18: 476-478.

21. Jose, A. D., and F. Stitt. 1967. Cardiac function after combined beta-adrenergic and cholinergic blockade. Relationship of intrinsic rate to contractile force of the heart in dogs. Circ. Res. Suppl. 21: 231-242.

22. Weissler, A. M., and C. L. Garrard. 1971. Systolic time intervals in cardiac disease. Mod. Concepts Cardiovasc. Dis. $40: 1-4$.

23. Snedecor. G. W., and W. G. Cochran. 1967. Statistical Methods. Iowa State University Press. Ames, Iowa. 6 th edition.
24. Jackson, D. H., T. J. Reeves, L. T. Sheffield, and J. Burdeshaw. 1973. Isometric effects on treadmill exercise response in healthy young men. Am. J. Cardiol. $31: 344-350$

25. Lind, A. R., G. W. McNicol, and K. W. Donald. 1966. Circulatory adjustments to sustained (static) muscular activity. In Physical Activity in Health and Disease. $\mathrm{K}$. Evang, editor. Universitets Forlaget, Oslo. 38-63.

26. Freyschuss, U. 1970. Elicitation of heart rate and blood pressure increase on muscle contraction. J. Appl. Physiol. 28 : 758-761.

27. Blinks, J. R. 1956. Positive chronotropic effect of increasing right atrial pressure in the isolated mammalian heart. Am. J. Physiol. 186: 299-303.

28. Robinson, B. F., S.E. Epstein, G. D. Beiser, and E. Braunwald. 1966. Control of heart rate by the autonomic nervous system. Studies in man on the interrelation between baroreceptor mechanisms and exercise. Circ. Res. 19 : 400-411.

29. Leon, D. F., J. A. Shaver, and J. J. Leonard. 1970. Reflex heart rate control in man. Am. Heart J. 80: 729-739.

30. Goodwin, G. M., D. T. McCloskey, and J. H. Mitchell. 1971. Cardiovascular and respiratory responses to changes in central command during isometric exercise at constant muscle tension. J. Physiol. (Lond.). 219: $40-41$.

31. Jones, R. D., and R. M. Berne. 1964. Intrinsic regulation of skeletal muscle blood flow. Circ. Res. 14: 126138.

32. Berne, R. M., and M. N. Levy. 1972. Cardiovascular Physiology. The C. V. Mosby Co., St. Louis. 2nd edition. 116-138.

33. MacDonald, H. R., R. P. Sapru, S. H. Taylor, and K. W. Donald. 1966. Effects of intravenous propranolol on the systemic circulatory response to sustained handgrip. Am. J. Cardiol. 18: 333-344.

34. Dunlop, D., and R. G. Shanks. 1968. Selective blockade of adrenoceptive beta receptors in the heart. $B r . J$. Pharmacol. Chemother. 32: 201-218.

35. Gibson, D. G., and D. J. Coltart. 1972. Hemodynamic effects of practolol. Br. Heart J. 34 : 95-99.

36. Goldstein, R. E., C. A. Hall, and S. E. Epstein. 1971. Comparison of simultaneously determined inotropic and chronotropic effects of practolol and propranolol. Clin. Res. 19: 316. (Abstr.)

37. Bevegård, B. S., and J. T. Shepherd. 1967. Regulation of circulation during exercise in man. Physiol. Rev. 47: 178-213.

38. Weissler, A. M., W. S. Harris, and C. S. Schoenfeld. 1969. Bedside technics for the evaluation of ventricular function in man. Am. J. Cardiol. 23: 577-583.

39. Martin, C. E., J. A. Shaver, M. E. Thompson, P. S. Reddy, and J. J. Leonard. 1971. Direct correlation of external indices of left ventricular function in man. Circulation. 44: 419-431.

40. Talley, R. C., J. F. Meyer, and J. L. McNay. 1971 Evaluation of pre-ejection period as an estimate of myocardial contractility in dogs. Am. J. Cardiol. 27: 384-391.

41. Metzger, C. C., C. B. Chough, F. W. Kroetz, and J. J. Leonard. 1970. True isovolumic contraction time. Correlation with two external indexes of ventricular performance. Am. J. Cardiol. 25 : 434-442.

42. Martin, C. E., J. A. Shaver, and J. J. Leonard. 1972. Physical signs, apexcardiography, phonocardiography 
and systolic time intervals in angina pectoris. Circulation. 46: 1098-1114.

43. Harris, W. S., C. D. Schoenfeld, and A. M. Weissler. 1967. Effects of adrenergic receptor activation and blockade on systolic preejection period, heart rate, and arterial pressure in man. J. Clin. Invest. 46: 1704-1714.

44. Frank, M. N., and N. Haberern. 1971. The effect of hand grip and exercise on systolic time intervals in human subjects. Am. J. Med. Sci. 261 : 219-223.

45. Siegel, W., C. A. Gilbert, D. O. Nutter, R. C. Schlant, and J. W. Hurst. 1972. Use of isometric handgrip for the indirect assessment of left ventricular function in patients with coronary atherosclerotic heart disease. Am. J. Cardiol. 30: 48-54.

46. Temkin, L. P., S. Wolfson, and L. S. Cohen. 1972. Dynamic (DYN) and isometric handgrip (IHG) exercise effects on systolic time intervals (STI) in normals (N) and patients with coronary artery disease (CAD). Clin. Res. $20: 400$. (Abstr.)

47. Krayenbuehl, H. P., W. Rutishauser, M. Schoenbeck, and I. Amande. 1972. Evaluation of left ventricular function from isovolumic pressure measurements during isometric exercise. Am. J. Cardiol. 29: 323-330.

48. Shaver, J. A., F. W. Kroetz, J. J. Leonard, and H. W. Paley. 1968. The effect of steady-state increases in systemic arterial pressure on the duration of left ventricular ejection time. J. Clin. Invest. 47: 217-230.

49. Epstein, S. E., D. R. Redwood, R. E. Goldstein, G. D. Beiser, D. R. Rosing, D. L. Glancy, R. L. Reis, and E. B. Steinson. 1971. Angina pectoris : pathophysiology, evaluation and treatment. Ann. Intern. Med. 75: 263296.

50. Sarnoff, S. J., E. Braunwald, G. H. Welch, Jr., R. B. Case, W. N. Stainsby, and R. Macruz. 1958. Hemodynamic determinants of oxygen consumption of the heart with special reference to the tension-time index. Am. J. Physiol. 192 : 148-156.

51. Redwood, D. R., D. R. Rosing, R. E. Goldstein, G. D. Beiser, and S. E. Epstein. 1971. Importance of the design of an exercise protocol in the evaluation of patients with angina pectoris. Circulation. 43: 618-628. 